\title{
Objectives and Content of the School Environmental Projects in Terms of Teachers' Training
}

\author{
Maria Kalathaki ${ }^{1, *}$ \\ ${ }^{1}$ School Advisor for Science Teachers in Secondary Education, Regional Educational \\ Directorates of Crete, Crete, Greece \\ *Correspondence: School Advisor for Science Teachers in Secondary Education, Regional \\ Educational Directorates of Crete, Knossos Avenue 6, Postal Code 71306, Heraklion, Crete, \\ Greece. E-mail: kalathakimaria.edu@gmail.com
}

Received: February 15, 2015 Accepted: March 16, 2015 Published: April 20, 2015

doi:10.5296/ije.v7i2.7467 URL: http://dx.doi.org/10.5296/ije.v7i2.7467

\begin{abstract}
This research is interested in checking whether the content of the school projects of Environmental Education falls within the field of Adult Education. If these projects offer, indirectly, in-school teachers' training because the participated teachers are simultaneously educators and learners, trainers and trainees, as long as they co-construct each environmental program jointly. This research focused not only on the setting goals and objectives but also on whether the development of the content are being structured in the frame of Environmental and Adult Education. It was carried out a case study, content analysis with analysis of texts of archival material of the submitted programs into the Secondary Education Secretariat of Heraklion Crete of Greece during 2005-2006 school year, as combination of qualitative and quantitative analysis.
\end{abstract}

Keywords: In-school teachers training, Program Evaluation, Environmental Education, Educational goals and aims 


\section{Introduction}

Teachers play a special role in societal change. They shape students' world view, attitudes towards the environment and the communities. Teachers educate future leaders, professionals, workers, parents and citizens of the world. Thus, teacher education and training, is of great importance for introducing sustainability in the classrooms (McKeown and Hopkins, 2002: 252 in Mageswary et al, 2011). Consequently, the education and training of teachers is a crucial element in the modernisation of European education and training systems in the overall level of process towards the common objectives of the 'Education and Training 2010' work programme (CRG, 2007). There is a great diversity in teachers' education and training all over Europe. The Commission has made a series of proposals improving the quality of teacher education (CEC, 2007). These include: a. ensuring that all teachers have the required knowledge, attitudes and pedagogic skills to be effective, $b$. ensuring that the provision for teachers' education and professional development is coordinated, coherent, and adequately resourced, c. promoting a culture of reflective practice and research among teachers, $d$. promoting the status and recognition of the teaching profession, e. supporting the professionalizing of teaching. The eight key competences identified by the European Council include communication in the mother tongue, communication in foreign languages, basic competences in maths, science and technology, digital competence, learning to learn, interpersonal, intercultural and social competences, and civic competence, entrepreneurship cultural expression (CEC, 2007). These key competences set new demands upon teachers. The head of all is redefinitions on teacher education, which, in some countries, focuses on the learning outcomes of the education curricula ensuring that teachers are very well equipped to implement a competence-based approach of learning. These learning outcomes are described as basic competences of knowledge, skills and attitudes that a graduated teacher needs to have acquired, related to their responsibility towards the learners, the school/educational community and society (CEC, 2009).

One of the challenges of teaching today is identifying and teaching strands of sustainability in national, provincial/state, and local primary and secondary curriculum, e.g., ecological principles in science, civil and human rights in social studies, and risk in health (Mckeown, 2012). These strands are not taught as part of the Education for the Sustainable Development (ESD), lack arises from the fact that, for the majority of today's teachers, ESD was not part of their education or initial training or ongoing professional development. Recognising sustainability as related content and didactic package skills, there is the need to be part of a reoriented of teacher education and training in order teaching to meet the demands of ESD in the reconstructed educational systems of Europe. Towards the same direction, the goal of lifelong Environmental Education (EE) is environmental literacy for all citizens, as a continuum of competencies, understanding, skills, and actions, rather than a discrete attribute that one either does or does not possess (Roth, 1992). For example, the majority of the goals of primary teachers' training in Croatia, that were recognized as related to information literacy, are linked to the development of critical thinking skills, problem solving and decision making, which are popular terms in professional literature (Kokić, 2012). The question remains, how do teacher educators teach these skills in their courses, in the frame of 
ESD. Hence, in order for teacher education departments to properly serve as advocates of ESD (Ojedokun, 2012), more answers have to be provided to questions such as, what should the content of ESD be? What methods and strategies should be theorised about and expatiate upon? How could the ESD be introduced into the school subjects' curriculum? It is believed that if the right answers are derived, it could adequately prepare well equipped pre-service teachers to become further advocates of ESD. It is also believed that a reflective understanding and application of the issues discussed in the context "Diffusion of Innovation Theory" could provide some relevant insights. ESD, is an innovation to which youth must be exposed in order to play future roles in the communities that will participate, even as educators, also as citizens who must contribute to stem the tide of global environmental problems such as earthquake, flooding, desertification, loss of biodiversity, climate change, global warming and feeding, etc (Ojedokun, 2012). The Earth Charter 2000 is one of the most important resources for the development of the content and practice of secondary school education. Furthermore, the sustainable development 'knowledge carriers' (teachers, advanced students, invited SD practitioners) establish active collaboration with other members of communities (parents, neighbours, students of other classes and different schools, experts, representatives of local government) and promote integration of SD values in all social activities (Savelava et al, 2010). If each item is expanded to include multiple indicators representing a specific dimension, it may be possible to develop a more comprehensive multidimensional measure that is useful for the evaluation of specific dimensions of each educational project (Wong \& Yeung, 2003).

This research is interested in checking whether the content of the School Projects of Environmental Education (SPEE) falls within the field of EE and satisfies the goals and aims of the EE and Adult Education (AE), regarding the common objectives, and if SPEE can be considered in-school teachers' self-training programs. Teachers participated in SPEE are simultaneously educators and learners, trainers and trainees, addressing to their students and themselves, as long as they co-construct each environmental program jointly. This research tried to answer in two research questions: what goals and objectives set SPEE and which is their program content, in the frame of EE and AE.

\section{Methodology}

The purpose of this study was the evaluation of the objectives and content of the SPEE, if they were identified in the frame of $\mathrm{EE}$ and $\mathrm{AE}$ and, consequently, they are suitable for the in-school teachers' self-training.

The research methodology was a case study content analysis, discourse analysis of archival material (Bell, 1997; Bird et al, 1999; Iosifidis, 2003) with a base unit recording the phrase and the paragraph. The research sample consisted of archival material of the submitted SPEE to the Secondary Education Secretariat of Heraklion Crete of Greece during 2005-2006 school year, consisted of 22 Application Forms (AF) in printed form, corresponding to 22 Final Reports (FR) in printed and electronic form, and texts written by some of the teachers-coordinators of the projects, assessing benefits obtained from the participation in 
these projects. The triangulation was a key objective of this research so it collected data from more than one source, and became a combination of qualitative and quantitative methods to quantify qualitative data (Cohen \& Manion, 1994; Iosifidis, 2003). Eight of these projects had been evaluated and approved for funding by the Aegean University. The archival material of FRs consists of texts, presentations, songs, music, photos, videos, studied as one group. The AFs had two standard types, named as SYP-A, appropriate for the Aegean University, and SYP-B, appropriate for the Secondary Education Secretariat. SPEEs were divided into two groups: group A consisted of 8 programs that had been approved for funding by the Aegean University and group B of the rest 14 projects.

The organization of the data in categories preferred not to be encoded by using a known software for the classification of the recording unit, because it did not use the same recording unit for the classification of all the survey data, and because of the variety and diversity of meanings contained and assigned to the educational material which is differentiated and is difficult to be distinguished through such diverse projects.

The criteria correspond to the research subjects and queries are 15, contained in the Evaluation Tool for the Greek Environmental Teachers' Training Programs by Kalathaki (2015) as analysed in the results below. Scoring of criteria was made in 0-4 five-point scale, based on the contents of the archive data. 0: no evidence to satisfy the objectives of EE and AE. 1: limited, weak link to the EE and AE objectives, 2: moderate, 3: substantial, strong satisfaction, 4: the design and implementation of the program coincided with the EE and AE projects' goals and aims, so the project was judged effective for in-school training of the teachers involved. For scoring criteria, became critical reading of the documents, kept notes, comments and interpretations of the total archival material. The content of the AFs and FRs was examined in such a way as to seek specific types of information, by quantifying the qualitative analysis and more specifically, discourse analysis of the non-structured, studied material (Bell, 1997; Iosifidis, 2003). All recorded observations and comments were taken into account for the final score of each criterion. The scoring of each criterion reveals the degree of harmonization with the aims of the $\mathrm{EE}$ and $\mathrm{AE}$ for school teachers who carry out SPEEs.

The statistical analysis of quantified data was done by using specialized software Statistical Package for Social Sciences (SPSS). Frequencies (N) and \% relative frequencies (percentages) exported per criterion, which are displayed in each cell of the result tables, corresponding to each grading scale. In essence, the 0 represents the interval $[0,0.5), 1$ the interval $[0.5,1.5)$ and so on. Additionally, the non-parametric test Wilcoxon \& Mann-Whitney applied to the criteria for the comparison of SYP-A and SYP-B of the AFs.

For the comparison of SYP-A and SYP-B were used the non-parametric test Wilcoxon W. \& Mann-Whitney U with p-values. The control to the research sub-queries was based on all the scores of all criteria satisfying of each sub-query. Statistical analysis was done at $8 \mathrm{SYP}-\mathrm{A}$ and at 14 SYP-B and the audit results are shown in Table 1 . If $\mathrm{p}$-value is $<0.05$, there is statistically significant difference. 
Table 1. P-values per sub-queries to which became non-parametric test Wilcoxon W. \& Mann-Whitney $\mathrm{U}$. If $\mathrm{P}$-value is $<0.05$, there is statistically significant difference

\begin{tabular}{lll}
\hline Research Question & Research Sub-queries & P-values \\
\hline $\begin{array}{l}\text { I. Determination of the goal and } \\
\text { objectives of the project }\end{array}$ & IIA. Clarification of the goal of the project & 0,868 \\
II. Description of the project & IIB. Analysis of the objectives of the project & 0,212 \\
content & IIIB. Structuring of the project content & 0,042 \\
\hline
\end{tabular}

\section{Results}

\subsection{Determination of the Educational Goals and Aims of the Projects}

To answer the criteria of this research question found sufficient information in all types of archival material, as explained below, although both types of AFs haven't specific area to record the goal of the project, there is only for the aims. Goals and aims are derived, indirectly, from the activities described in the FRs. The results of the study of this research question are presented in Table 2.

\section{A. Setting the goals and aims of the projects}

At the conference of Tbilisi in 1977 analysed the goals, principles and characteristics of EE (UNESC, 2004; Flogaiti E., 1993; EMP, 2007). Main goal of EE is the capture of knowledge about the environment and the development of friendly attitudes and behaviours towards it. The environment is a huge school that should be used for the education of all. In the period up to 2020, the primary goal of European cooperation should be the support of further development of the education and training systems of the member states which aim at ensuring: the personal, social and professional fulfilment of all citizens, sustainable economic prosperity and employability, whilst promoting democratic values, social cohesion, active citizenship, and intercultural dialogue (CEU, 2009).

Relevance of the project to meet the educational needs of the target population. The objective of personalisation has become pivotal in discussions about the future of the education and education policies. Today it is recognised that "one size fits all" ideology applied to learning does not correspond to the needs of the individuals and a knowledge-based society (Volmari et al, 2009). A traditional education and training system provides individuals with almost identical competences, while at the same time the labour market needs professionals with varying skills and knowledge. Thus, the education and training should produce professionals who, within the requirements of their qualifications, will be able to specialise and personalise studies to suit their capabilities, interests and future aims.

Based on the analysis of the majority of the archival material, the projects appear very appropriate to meet the educational needs of the target population of students and the teachers from the point of the present investigation. Tsetsilas (2006), in a case study in a Greek Primary school, found that the training needs of teachers were on the relations and cooperation with the school environment (students, parents, local community and 
authorities).

\section{B. Analysis of the aims of the projects}

The aims of the projects may not be written very detailed in AFs, but they are very well arising from the FRs, deriving from the implemented activities. The Conference of Tbilisi in 1977 identified five categories of targets to be acquired by individuals and groups through EE: awareness and sensitivity towards the environment and environmental problems, knowledge and understanding of the environment and environmental problems, attitude towards, interest and care for the environment, skills to identify and solve environmental problems and active participation in solving environmental problems (UNESC, 2003). A goal that seems to be imperative at the teachers' training programs is the fair use of information, as future teachers in their work will frequently deal with, such as imitation and plagiarism, multiple copying of copyrighted materials, and so on. The analysis of course descriptions revealed that least focus was given to fair use of the collected information. Knowing the high importance and actuality of the fair use of issue in educational environments, this finding should be also reviewed from the wider sociological scope, as also Kokić (2012) notes.

Participation of the trainees in formulation of the project objectives. The themes of the environmental projects and its objectives should be decided jointly by students and teachers (Anastasatos, 2007). Teachers should encourage students by creating comfortable classroom climate, to express their concerns, experience and desires to specific issues. Many investigations (Tsetsilas, 2006; Katarahia, 2007; Agelidou \& Kritikou, 2005) emphasize that teachers perceive very positively their participation in planning and organizing training programs because they believe that a training program, designed by themselves, will respond much more to their needs. At SPEE, they have the chance of designing, building up and applying by themselves the whole project. The survey revealed that students, generally, do not participate in the project objectives setting, work undertaken mainly by the teachers. The score of SYP-A was clearly better after half scored high.

Assignment of the project objectives to the educational needs of the target population. Having not done exploring of the educational needs of the students, who are the target population of the program, or at least do not mentioned in the AFs and FRs that have been done, the goals and aims of the projects set by the teachers. The scoring of AFs and FRs was based on whether the goals and aims serve the needs of the project, which must represent the needs of trainees. Ratings were modest. The study of the objectives of SPEE of Lassithi prefecture of Crete, in school year 2004-2005, showed that most projects are riveted in a shallow environmentalism (Drakonaki, 2006) because about half of them sought to provide students with knowledge about the environment while a smaller number developed problem solving skills. To conclude, most programs are satisfied with the mere knowledge of phenomenon or limited to the identification of some problems, without offering the opportunity to develop skills of investigation and solving environmental problems.

Appropriateness of the educational goals to meet the needs of the target population. The appropriateness of educational objectives to meet the needs of the target population, students and teachers, was, generally, good. 
Realism in achieving the objectives. The realism of the project objectives, in this criterion, was based on the goals and activities originally planned in AFs and activities that were made eventually and described in FRs. In SPEE, goals were usually placed at the beginning, later some changes were added or removed along the way. At the end, as the research revealed, almost all were fulfilled indeed satisfactorily. The proposals of the projects were sufficiently complete and clear. Almost all the teachers seemed to put realistic goals in projects design and implement, as evidenced by the high scores on the corresponding criterion. In this criterion occurs, however, the following non sequitur. Regarding the realism of targets, three projects (A1, A2, A6) were characterized by low realism to their targets because they seemed quite ambitious and difficult to achieve from the evidence given in the AFs. These projects, while scored very high on other criteria, took low score to this. The duration of the first two projects was two years, while all the others were one year as usually, and the third carried out sports activities in nature, which were considered extremely difficult to implement as unusual for environmental teams. As it turned out in the FRs, these goals and aims were achieved to a significant level, so finally, they turned out to be realistic. In contrast to the above, in a survey of the Greek Pedagogic Institute, Spyropoulou (2000), in a Greek research, was found an unspecified content and grand aims without hierarchy of instructional interventions in the design and implementation of the SPEE. Consequently, the effectiveness of these projects is under questioning.

Setting objectives based on the knowledge and skills to be acquired. In none SPEE, mention being made in the exact, one by one, match of targets and knowledge/skills that were intend to be developed. The listed objectives were general and specialized in specific knowledge and skills. Teacher T3 wrote that "dealing with the surrounding environment stimulates students to be more involved, to become better in their lessons and to help their homeland (socialization)".

Setting objectives on the basis of the socio-political and cultural environment where the new knowledge and skills will be used. The objectives of SPEE ought to be cognitive, scientific, social, aesthetic and self-educative (EMP, 2007). Of course, in the development of this criterion contributes significantly the nature of the subject, so the rating varied, but it was generally good.

\subsection{Description of the Project Content}

EE and ESD are broad fields for the development of educational activities in the areas of art, history, sciences, technology, new technologies, sports, culture, which contribute to the formation of values, attitudes, knowledge and general education, to the cultivation of critical capacity and flexibility in dealing with situations and undertaking initiatives. The school initiatives within the ESD school projects in United Kingtom focus on specific issues of everyday school life, the local environment and expand globally (Scott, 2007; DfES, 2006).

To answer all the criteria of this research question, data was found in all types of the archival material, as explained below. In SYP-B was not easy to fully understand the content of the project because there was no field for filling but from other fields and parts of the projects, revealed much more, such as the FRs, that drawn enough information. The results of this 
research question are displayed in the Table 3.

\section{A. Analysis of the Project Content}

An adult education project is structured into three levels: knowledge for theoretical training, practical work for developing skills and competencies of learners that are required to carry out the planned activities and the development of positive attitudes and behaviours (Kapsalis \& Papastamatis, 2000).

Proper documentation and completeness of the content of the program. The criteria for the pedagogical approach of the natural object of the project, according to Aegean University (website Aegean/sppe, 2005), check the interdisciplinary handling of environmental issues, the connections to the basic principles of intercultural and experiential education, the nature of the research, the learner-centred of projects, the responsiveness to general specifications which correspond to the stages of cognitive development of the children, etc. The rating of the AFs was good and even better of the FRs. The relatively high scores recorded in the criterion for proper documentation and completeness of the content of the project in contradiction to Spyropoulou (2000) observations which, in an earlier investigation on archival material of SPEE, found to have unspecified content. Apparently, Greek SPEE improved rapidly the design and construction during the intervening decade.

Analysis, clarification and clear description of the physical object of the project. The content of a teachers' training project of the EE, as AE project, needs to have proper documentation, completeness of analysis and clarification, clear description of the object, connection to everyday life, adequacy to meet training needs and project objectives. The project should be oriented to environmental issues, to develop skills and competencies for the solution of environmental issues through a holistic approach between the school and the local community (Flogaiti, 1993, 2006). SYP-A had a very good way of describing the natural object of the project, thus it got the maximum score in $87.5 \%$ (7/8 programs). Half of the SYP-B of group B took maximum points while SYP-B of group A were better, since $3 / 4$ of them took point 4 .

Connection with Daily Life. The reason for choosing the topic of the project can be any current event in the news eg. genetic modified organisms or a problem of the area such as open spaces, pollution, fires, epidemics. The importance of the link of SPEE with daily life and the local environment seems to have been perceived in most projects, such as experienced by the teacher T3: "When two years ago started this environmental education project, involving the recording of the natural and cultural resources I did not expect that a relatively small area, was hiding so much natural and cultural richness".

Suitability to meet training needs and objectives. The content of a student teaching project must be consistent with the educational needs, interests, characteristics and experiences of learners, their socio-economic and educational level, the available time they can participate in the project (Frangoulis, 2006). The projects were judged suitable to meet, in relatively high level, the training needs and objectives of students and teachers, as occurred high enough rating scores, $75 \%$ of SYP-A and $45,5 \%$ of SYP-B took grade 4. 


\section{B. Structuring of the project content}

In the sub-queries of selecting and structuring the project content, SYP-A outweigh standing SYP-B with corresponding p-values 0,042 and 0,006, enabling more detailed development of several fields design and structuring of the project content, not in goals and aims. The type of AF of SYP-A offers the possibility to the teachers to analyse thoroughly students' and their ideas on the natural object of the project because it has more sub-fields for detailed filling than the simpler SYP-A form.

According to Roths (1992), three levels of environmental literacy (nominal, functional, operational) can be a framework for leaders of adult learners to structure projects for different audiences and to help learners progress to higher levels of environmental sophistication throughout a lifetime of learning. At the very least, what is needed in American teacher education project is a comparative education, courses that can help teacher develop skills of cross-cultural examination and critical reflection, so that they can recognize and evaluate all the changing that are shaping their lives and work (Kubow, 2011). Ojedokun (2012) focuses on the educational implications of the theory and suggests that curriculum of teacher education institutions must be reviewed to accommodate the learning content of ESD (e.g. climate change, green economy, democracy, equity and social justice, structural change, reclamation of social bonds, waste disposal/management/recycling) and theorising more on learner friendly approaches, so as to have a trickle down effects on the younger generation of school children who are the final recipients of the environment and social development.

Fulfilling the criteria related to the classification of the project content and the temporal succession of theoretical and practical training is of high importance of the nature of the project subjects and the objects that teachers choose to develop in.

Classification of the project content (matter distribution into sections, separation of theoretical training and exercise). The allocation of the project content into sections, separating theoretical and practical, is not clearly mentioned in all projects, that derives from the designed objectives and activities at AFs and eventually held on FRs. Clearer division seems to be in SYP-A where 75\% took the maximum grade. A survey of Tsetsilas (2006) for the training needs of teachers, particularly teachers emphasized the need for practice and not to theorize about the issues, position partly justified, since in the educational process they are invited to provide solutions to teaching and many other practical problems.

Levels of the construction of the project content by $a$. the knowledge of the trainees, $b$. the level of skills/competencies development with the practical exercise, $c$. the level of changing attitudes, values and behaviour in order to improve the communication capacity and collaborative ability of the trainees. To help create a sense of place in small communities for the students, and to show teachers that they don't need a scientific background of Ecology to teach EE, Johnston (2009) developed an arts and humanities based project called "Good Neighbours Come in All Species. The values which were identified as significant for the Civil Society Organizations and were confirmed from further analysis were unity in diversity, trust/trustworthiness, justice, empowerment, integrity and care/respect (Podger et al, 2010). 
Those above mentioned levels of building up projects of EE and AE were found, but not in all programs. The design of gradual development of the project best seen at the theoretical level and at developing skills and change attitudes, behaviours, and cooperativeness, as $75 \%$ of SYP-A took maximum points and approximately half of SYP-B (45.5\%).

Temporal sequence and rhythm of the project (total duration, duration of the theoretical training and practice). This criterion showed major shortages in SYP-B. More than half $(55 \%)$ of the projects scored at the lowest level, since, in the SPEE do not plan the timing of theoretical and practical education/training.

Fullness and clarity of the project proposal. The AFs of group A were sufficiently complete and clear in terms in this criterion since all SYP-A scored 4 and 9 of the 22 SYP-B (41\%).

\section{Conclusions}

The design of SPEE generally follows the rules of design quality projects of $\mathrm{EE}$ and $\mathrm{AE}$, according to the score obtained by the AFs and FRs in the analysis, clarification, documentation and description of project aims and content. The remarkable analogies show that at the same time and indirectly the school educational projects for the students, train also the teachers who undertake the materialization. SPEEs function as self and hetero-substituted training projects, inasmuch the educators and learners are the teachers, the students and external scientific and social collaborators. Teachers' motivation to engage with the EE at schools, are their personal interest in environmental problems and the desire to act to deal with them, as well as the opportunity to develop team spirit and interpersonal relationships for both among students and between teachers and students (Kalathaki, 2005; Mpatsi, 2006; Kyrdi, 2011). It is noteworthy that although SD not often mentioned in the projects, as demand of our days and direction of EU, it seems to be cultivated to a relatively high degree the target of the environmentally literate active citizen.

Table 2. Description of the Project Content- Rating Criteria of the School Environmental Projects (SPPE) of the sub-queries A (Determination of the goal of the project) and B (Analysis of the objectives of the project). Display of \% Relative Frequencies (up) and Frequencies (down) of the projects in the rating scale of $0-4$

\begin{tabular}{|c|c|c|c|c|c|c|c|c|c|c|c|c|c|c|c|c|c|c|c|c|c|c|}
\hline & \multirow[t]{2}{*}{$\begin{array}{l}\text { Sub- } \\
\text { queries }\end{array}$} & \multirow{2}{*}{$\begin{array}{l}\text { No of } \\
\text { Criterion/ } \\
\text { Grading } \\
\text { Scale } \\
\end{array}$} & \multicolumn{5}{|c|}{$\begin{array}{l}\text { PROJECT PROPOSALS } \\
(\mathrm{SYP}-\mathrm{A})(\mathrm{N}=\mathbf{8})\end{array}$} & \multicolumn{10}{|c|}{$\begin{array}{l}\text { PROJECT PROPOSALS (SYP-B) } \\
\text { Group A }(\mathrm{N}=\mathbf{8}) \text { / Group B }(\mathrm{N}=14)\end{array}$} & \multicolumn{5}{|c|}{$\begin{array}{l}\text { FINAL REPORTS (FRs) } \\
(\mathrm{N}=22)\end{array}$} \\
\hline & & & 0 & 1 & 2 & 3 & 4 & 0 & & 1 & & 2 & & 3 & & 4 & & 0 & 1 & 2 & 3 & 4 \\
\hline & \multirow[t]{6}{*}{ A } & 1 & 0,0 & 0,0 & 12,5 & 12,5 & 75,0 & 0,0 & 0,0 & 0,0 & 0,0 & 0,0 & 21,4 & 12,5 & 7,1 & 87,5 & 71,4 & 27,3 & 0,0 & 4,5 & 13,6 & 54,5 \\
\hline & & & 0 & 0 & 1 & 1 & 6 & 0 & 0 & 0 & 0 & 0 & 3 & 1 & 1 & 7 & 10 & 6 & 0 & 1 & 3 & 12 \\
\hline & & 1 & 12,5 & 25,0 & 12,5 & 0,0 & 50,0 & 0,0 & 7,1 & 75,0 & 78,6 & 0,0 & 0,0 & 12,5 & 14,3 & 12,5 & 0,0 & 40,9 & 9,1 & 9,1 & 9,1 & 31,8 \\
\hline & & & 1 & 2 & 1 & 0 & 4 & 0 & 1 & 6 & 11 & 0 & 0 & 1 & 2 & 1 & 0 & 9 & 2 & 2 & 2 & 7 \\
\hline & & 2 & 12,5 & 12,5 & 0,0 & 25,0 & 50,0 & 0,0 & 7,1 & 37,5 & 21,4 & 37,5 & 7,1 & 37,5 & 7,1 & 12,5 & 42,9 & 18,2 & 9,1 & 18,2 & 13,6 & 40,9 \\
\hline & & & 1 & 1 & 0 & 2 & 4 & 0 & 1 & 3 & 3 & 3 & 1 & 3 & 1 & 1 & 6 & 4 & 2 & 4 & 3 & 9 \\
\hline & \multirow[t]{8}{*}{ B } & 3 & 0,0 & 0,0 & 12,5 & 12,5 & 75,0 & 0,0 & 0,0 & 25,0 & 0,0 & 12,5 & 42,9 & 12,5 & 14,2 & 50,0 & 42,9 & 9,1 & 0,0 & 22,7 & 27,3 & 40,9 \\
\hline & & & 0 & 0 & 1 & 1 & 6 & 0 & 0 & 2 & 0 & 1 & 6 & 1 & 2 & 4 & 6 & 2 & 0 & 5 & 6 & 9 \\
\hline I & & 4 & 0,0 & 37,5 & 0,0 & 0,0 & 62,5 & 0,0 & 0,0 & 0,0 & 0,0 & 25,0 & 0,0 & 0,0 & 0,0 & 75,0 & 100,0 & 9,1 & 4,5 & 9,1 & 4,5 & 72,7 \\
\hline & & & 0 & 3 & 0 & 0 & 5 & 0 & 0 & 0 & 0 & 2 & 0 & 0 & 0 & 6 & 14 & 2 & 1 & 2 & 1 & 16 \\
\hline & & 5 & 12,5 & 0,0 & 0,0 & 25,0 & 62,5 & 0,0 & 0,0 & 25,0 & 14,3 & 12,5 & 28,6 & 50,0 & 14,3 & 12,5 & 42,9 & 9,1 & 4,5 & 18,2 & 13,6 & 54,5 \\
\hline & & & 1 & 0 & 0 & 2 & 5 & 0 & 0 & 2 & 2 & 1 & 4 & 4 & 2 & 1 & 6 & 2 & 1 & 4 & 3 & 12 \\
\hline & & 6 & 0,0 & 0,0 & 25,0 & 12,5 & 62,5 & 0,0 & 7,1 & 0,0 & 0,0 & 12,5 & 28,6 & 0,0 & 28,6 & 87,5 & 35,7 & 4,5 & 9,1 & 22,7 & 22,7 & 40,9 \\
\hline & & & 0 & 0 & 2 & 1 & 5 & 0 & 1 & 0 & 0 & 1 & 4 & 0 & 4 & 7 & 5 & 1 & 2 & 5 & 5 & 9 \\
\hline
\end{tabular}




\section{Mll Macrothink}

Table 3. Description of the Project Content- Rating Criteria of the School Environmental Projects (SPPE) of the sub-queries A (Analysis of the project content) and B (Structuring of the project content). Display of \% Relative Frequencies (up) and Frequencies (down) of the projects in the rating scale of $0-4$

\begin{tabular}{|c|c|c|c|c|c|c|c|c|c|c|c|c|c|c|c|c|c|c|c|c|c|c|}
\hline & \multirow[t]{2}{*}{$\begin{array}{l}\text { Sub- } \\
\text { queries }\end{array}$} & \multirow{2}{*}{$\begin{array}{l}\text { No of } \\
\text { Criterion/ } \\
\text { Grading } \\
\text { Scale } \\
\end{array}$} & \multicolumn{5}{|c|}{$\begin{array}{l}\text { PROJECT PROPOSALS } \\
(\mathrm{SYP}-\mathrm{A})(\mathrm{N}=\mathbf{8})\end{array}$} & \multicolumn{10}{|c|}{$\begin{array}{l}\text { PROJECT PROPOSALS (SYP-B) } \\
\text { Group A (N=8) / Group B (N=14) }\end{array}$} & \multicolumn{5}{|c|}{$\begin{array}{l}\text { FINAL REPORTS (FRs) } \\
(\mathrm{N}=22)\end{array}$} \\
\hline & & & 0 & 1 & 2 & 3 & 4 & 0 & & 1 & & 2 & & 3 & & 4 & & 0 & 1 & 2 & 3 & 4 \\
\hline & & 1 & 0,0 & 0,0 & 12,5 & 0,0 & 87,5 & 0,0 & 0,0 & 0,0 & 7,1 & 37,5 & 42,9 & 0,0 & 14,3 & 62,5 & 35,7 & 0,0 & 0,0 & 13,6 & 18,2 & 68,2 \\
\hline & & & 0 & 0 & 1 & 0 & 7 & 0 & 0 & 0 & 1 & 3 & 6 & 0 & 2 & 5 & 5 & 0 & 0 & 3 & 4 & 15 \\
\hline & & 2 & 0,0 & 0,0 & 0,0 & 12,5 & 87,5 & 0,0 & 0,0 & 0,0 & 0,0 & 0,0 & 35,7 & 25,0 & 14,3 & 75,0 & 50,0 & 0,0 & 0,0 & 18,2 & 13,6 & 68,2 \\
\hline & & & 0 & 0 & 0 & 1 & 7 & 0 & 0 & 0 & 0 & 0 & 5 & 2 & 2 & 6 & 7 & 0 & 0 & 4 & 3 & 15 \\
\hline & & 3 & 0,0 & 0,0 & 12,5 & 12,5 & 75,0 & 0,0 & 7,1 & 0,0 & 7,1 & 12,5 & 7,1 & 25,0 & 14,3 & 62,5 & 64,3 & 0,0 & 4,5 & 13,6 & 22,7 & 59,1 \\
\hline & $\mathbf{A}$ & & 0 & 0 & 1 & 1 & 6 & 0 & 1 & 0 & 1 & 1 & 1 & 2 & 2 & 5 & 9 & 0 & 1 & 3 & 5 & 13 \\
\hline \multirow{9}{*}{ II } & & & 0 & 1 & 0 & 1 & 6 & 0 & 2 & 1 & 0 & 0 & 5 & 1 & 3 & 6 & 4 & 0 & 1 & 6 & 7 & 8 \\
\hline & & 1 & 0,0 & 0,0 & 12,5 & 12,5 & 75,0 & 0,0 & 0,0 & 25,0 & 57,1 & 12,5 & 14,3 & 0,0 & 7,1 & 62,5 & 21,4 & 0,0 & 13,6 & 27,3 & 18,2 & 40,9 \\
\hline & & & 0 & 0 & 1 & 1 & 6 & 0 & 0 & 2 & 8 & 1 & 2 & 0 & 1 & 5 & 3 & 0 & 3 & 6 & 4 & 9 \\
\hline & & 2 & 0,0 & 0,0 & 25,0 & 0,0 & 75,0 & 0,0 & 0,0 & 0,0 & 14,3 & 50,0 & 42,9 & 0,0 & 14,3 & 50,0 & 28,6 & 0,0 & 0,0 & 36,4 & 31,8 & 31,8 \\
\hline & & & 0 & 0 & 2 & 0 & 6 & 0 & 0 & 0 & 2 & 4 & 6 & 0 & 2 & 4 & 4 & 0 & 0 & 8 & 7 & 7 \\
\hline & B & 3 & 0,0 & 0,0 & 25,0 & 12,5 & 62,5 & 0,0 & 0,0 & 25,0 & 71,4 & 12,5 & 0,0 & 37,5 & 7,1 & 25,0 & 21,4 & 0,0 & 13,6 & 27,3 & 22,7 & 36,4 \\
\hline & & & 0 & 0 & 2 & 1 & 5 & 0 & 0 & 2 & 10 & 1 & 0 & 3 & 1 & 2 & 3 & 0 & 3 & 6 & 5 & 8 \\
\hline & & 4 & 0,0 & 0,0 & 0,0 & 0,0 & 100,0 & 0,0 & 0,0 & 0,0 & 0,0 & 12,5 & 28,6 & 25,0 & 42,9 & 62,5 & 28,6 & 0,0 & 0,0 & 0,0 & 0,0 & 0,0 \\
\hline & & & 0 & 0 & 0 & 0 & 8 & 0 & 0 & 0 & 0 & 1 & 4 & 2 & 6 & 5 & 4 & 0 & 0 & 0 & 0 & 0 \\
\hline
\end{tabular}

\section{References}

Anastasatos N. (2007). Project Method in Environmental Education, Academic Notes. Graduate Program Environmental Education, TEPAES, University of the Aegean, Rhodes

Angelidou E., \& Critikou E. (2005). Motives for teachers in environmental education programs and reasons for discontinuation of participation in Secondary Education of Eastern Attica, 2nd National Symposium Inspiration Meditation and Imagination in Environmental Education, University of Piraeus, 1-3 April.

Bell J. (1997). Methodological design of Pedagogic and social Research. Gutenberg Publications, Athens.

Bird M., Hammersley M., Gomm R., \& Woods P. (1999). Educational Research in Action. Translation into Greek by Frangou E under the title Educational Research in Practice-study manual, Patras.

CEC (2007). Improving the Quality of Teacher Education, Communication from the Commission to the Council and the European Parliament, -Commission of the European Communities Com(2007) 392, Sec(2007) 931, Brussels, 3.8.2007.

CEC (2009). Key competences for a changing world. Progress towards the Lisbon objectives in education and training, Analysis of implementation at the European and national levels, Commission of the European Communities, Brussels, 25.11.2009. SEC(2009) 1598. $\operatorname{COM}(2009) 640$.

CEU (2009). Council Conclusions on a strategic framework for European cooperation in education and training ("ET 2020") 2941th, Education, Youth and Culture, Council of the European Union, Council meeting, Brussels, 12 May. 


\section{Macrothink}

International Journal of Education ISSN 1948-5476 2015, Vol. 7, No. 2

Cohen, L., \& Manion, L. (1994). Research Methods in Education (4th ed.). London: Routledge.

CRG (2007). Conclusions of the Council and the Representatives of the Governments of the Member States on Improving the Quality of Teacher Education. Meeting within the Council of 15 November, Official Journal of the European Union 12.12.2007 IV, Notices From European Union Institutions and Bodies, (2007/C 300/07).

DfES (2006). Sustainable Schools for pupils, communities and the environment Government response to the consultation on the sustainable schools strategy. Retrieved from

http://publications.teachernet.gov.uk/default.aspx?PageFunction=productdetails\&PageM ode=publications\&ProductId=DFES-04294-2006

Drakonaki X. (2006). Environmental Education in the Schools of Lasithi prefecture, $2^{\text {nd }}$ Congress of School environmental Programs, Athens 15-17 December.

EMP (2007). Training material for the Seminar of Teachers and Education Officials on Environmental Education, EPEAEKII, Writing Team with coordinator Koutsopoulos K., National Technical University of Athens.

Flogaiti E. (1993). Environmental Education. Greek University Press.

Flogaiti E. (2006). Education for the Environment and the sustainability, publishing Greek Letters, $2^{\text {nd }}$ ed, Athens.

Frangoulis I. (2006). Design and development of Quality Indicators for the Evaluation Programs Local History in Primary Education, 5th National Conference Company Greece Pedagogy, Thessaloniki 24-26 November 2006.

Iosifidis Th. (2003). Analysis of Qualitative data in Social Sciences. Kritiki Publications, Athens.

Johnston J. (2009). Transformative Environmental Education: Stepping Outside the Curriculum Box. Canadian Journal of Environmental Education, 14.

Kalathaki M. (2005). Role of the coordinator of the school environmental program. $1^{\text {st }}$ Congress of School Environmental Programs, 23-25 of September, Korinthia, Greece.

Kalathaki M. (2015). Evaluation tool for teachers' training projects of Environmental Education. International Journal of Education, 7(1).

Kapsalis A., \& Papastamatis A. (2000) Adult Education, vol B, Adult Teaching, University publications, University of Macedonia, Department of Educational and Social Policy, Thessaloniki.

Katarahia S. (2007). Investigation of educational needs of secondary school teachers on Education Environmental Education of the Prefecture of Piraeus, Thesis, Greek Open University, Patras. 
Kokić (2012). Information Literacy for Future Teachers. World Journal of Education, 2(1), $45-54$.

Kubow P. K. (2011). Teacher Education Worldwide and the United States Case into Teacher Education in Modern Era. Trends and Issues by Anastasiades P., Calogiannakis P., Karras K., Wolhuter C.C. (editors), University of Crete, Department of Primary Education, Pedagogical Institution. Retrieved 9/8/13 from http://www.epimorfosi.edu.gr/images/stories/ebookeng/ebook_englsih_final.pdf

Kyrdi K. (2011) Educational potential of voluntary programs of school activities. In Bagakis G. (2011) (eds.), Statutory and new forms of training. Looking for synergies and best practices, Agency of Teacher Training (OEPEK), ISBN 978-960-99912-8-5.

Mageswary K., Zurida I., \& Norita M. (2011) Greening a Chemistry Teaching Methods Course at the School of Educational Studies, Universiti Sains Malaysia. Journal of Education for Sustainable Development, 5, 197. http://jsd.sagepub.com/content/5/2/197

Mckeown R. (2012). Teacher Education 1992 and 2012: Reflecting on 20 Years. Journal of Education for Sustainable Development, 6, 37.

Mpatsi Th. (2007). Environmental Education and Teachers. A case study of the Primary Schools teachers of Rethymnon prefecture, Thesis, Open University, Patra.

Ojedokun O. (2012). Diffusing Education for Sustainability into Teacher Education Programme in Nigeria: A Theory in Use. World Journal of Education, 2(2)

Podger D., Piggot G., Zahradnik M., Janousková S., Velasco I., Hak T., Dahl A., Jimenez A., \& Harder H. (2010). The Earth Charter and the ESDinds Initiative: Developing Indicators and Assessment Tools for Civil Society Organisations to Examine the Values Dimensions of Sustainability Projects. Journal of Education for Sustainable Development, 4, 297.

Roth, C. E. (1992). Environmental literacy: Its roots, evolution, and directions in the 1990s. Columbus, OH: ERIC/CSMEE.

Savelava S., Savelau D., \& Bakhnova Cary M. (2010). Practicing ESD at School: Integration of Formal and Nonformal Education Methods Based on the Earth Charter (Belarusian Experience). Journal of Education for Sustainable Development, 4(2), 259-269

Scott W. (2007), Goodfellow M., \& Andrew-Power K. (editors). Raising standards: making sense of the sustainable schools agenda, Specialist Schools and Academies Trust, London.

Spyropoulou D. (2001). Assessment of the Environmental Education during the decade 1991-2000. Retrieved 31-10-2007 from http://www.pi-schools.gr/download/publications/epitheorisi/teyxos5/

Tsetsilas I. (2006). Record of training needs of teachers and design training programs: The case study of a school unit of Primary Education with model DION, Thesis, Patras. 
UNESC (2003). Statement on education for sustainable development by the UNECE Ministers of the environment Fifth Ministerial Conference "Environment for Europe" Kiev, Ukraine, 21-23 May 2003, ECE/CEP/102/Rev.1, 13 June 2003.

UNESC (2004). Draft UNECE Strategy for Education for Sustainable Development, Addendum, Background, 2nd Regional Meeting on Education for Sustainable Development, Rome, 15-16 July 2004, cep/ac.13/2004/8/add.1, 18May 2004, Economic Commission for Europe Committee on Environmental Policy.

Volmari K., Helakorpi S., \& Frimodt R. (2009). Competence Framework for Vet Professions, Handbook for practitioners, Finnish National Board of Education and Editors, ISBN 978-952-13-4118-2, Vammalan Kirjapaino Oy, Sastamala.

Wong E., \& Yeung A. (2003). Evaluation of teacher development programs: participant satisfaction and recommendation. Studies in Educational Evaluation, 29, 57-66.

\section{Copyright Disclaimer}

Copyright for this article is retained by the author(s), with first publication rights granted to the journal.

This is an open-access article distributed under the terms and conditions of the Creative Commons Attribution license (http://creativecommons.org/licenses/by/3.0/). 